\title{
Petrography and Micromorphology Face-to-Face: the Potential of Multivocality in the Study of Earth-Based Archaeological Materials
}

\author{
Susanna Cereda ${ }^{1 *}$, Pamela Fragnoli ${ }^{2}$ \\ ${ }^{I}$ University of Innsbruck, Institute of Archaeologies, Langer Weg 9-11, 6020 Innsbruck, Austria \\ ${ }^{2}$ Austrian Archeological Institute, Austrian Academy of Sciences, Franz Klein-Gasse 1, A-1190 Wien, Austria
}

\section{ARTICLE INFO}

Article history:

Received: $14^{\text {th }}$ September 2020

Accepted: $3^{\text {rd }}$ March 2021

DOI: http://dx.doi.org/10.24916/iansa.2021.1.1

\section{Key words:}

earthen materials

polarising microscopy

micromorphology

ceramic petrography

tell sites

Arslantepe

\begin{abstract}
A B S T R A C T
Soils and sediments are among the most commonly found materials in archaeological contexts, occurring in a myriad of forms. We need only think of pottery, which is a manipulated and fired sediment, or the different earthen deposits that compose the bulk of many sites. Traditionally, the study of the microscopic and compositional characteristics of pottery has been the focus of ceramic archaeometry, while the microstratigraphic analysis of archaeological sediments was always the main task of geoarchaeology. In this paper, the authors explore the potential of a closer collaboration between researchers dealing with the same type of raw material and often using the same methods (optical microscopy), who rarely confront the approaches and expertise of the other field. For this purpose, two samples belonging to the pre-historic and early historic site of Arslantepe were selected for a methodological exercise: a fragment of an andiron and a piece of a double-vaulted oven. Ultimately, the results of this work demonstrate that researchers from both fields can profit from a more intense exchange: one that takes advantage of the expertise developed in answering distinct but complementary research questions, and calls for the blurring of strict inter-disciplinary boundaries.
\end{abstract}

\section{Introduction}

The implementation of techniques first developed in the field of geology or soil science to answer questions of archaeological relevance is not a novelty. After all, soils and sediments (from the fine clayey fraction to rocks) are a main component of any archaeological site. This omnipresent element can be found in a myriad of forms, and one of the most common at least from the onset of this technology - is pottery. Using the same concepts and methods established for the study of rocks, ceramic petrography cuts thin sections through the body of vessels in order to study the nature and spatial arrangement of both their coarse and fine components (Quinn, 2013). Even more abundant than pottery is the sedimentary fabric that composes the body of a site, and that derives primarily from constructed, collapsed or levelled buildings. The microscopic analysis of these sedimentary sequences is

*Corresponding author. E-mail: Susanna.Cereda@uibk.ac.at called micromorphology, and since the 1980s it has gained increasing attention in archaeology (Courty and Fedoroff, 1982; Goldberg, 1979; Goldberg, 1980; Stoops, 1984).

Although converging on the type of studied material and also on the wide adoption of optical microscopy for the observation of their samples, micromorphology and ceramic petrography are treated as two separate fields, since they aim at clarifying different aspects of past societies. Ceramic petrography deals with synthetic artefacts produced by humans through a specific sequence of operation (the so-called chaîne opératoire) in order to shed light on ancient technological behaviour and exchanges. Micromorphology looks at the microstratigraphy of a site in order to assess what events/agencies led to the deposition of a sequence and what post-depositional processes affected the stratigraphy. While the difference inherent in the research questions is clear, the distinction based on the type of materials analysed might be ambiguous and artificial. This concern, for example, earth construction materials, such as mudbricks, adobe, plaster, daub, concrete and mortars that fit both definitions, being as 


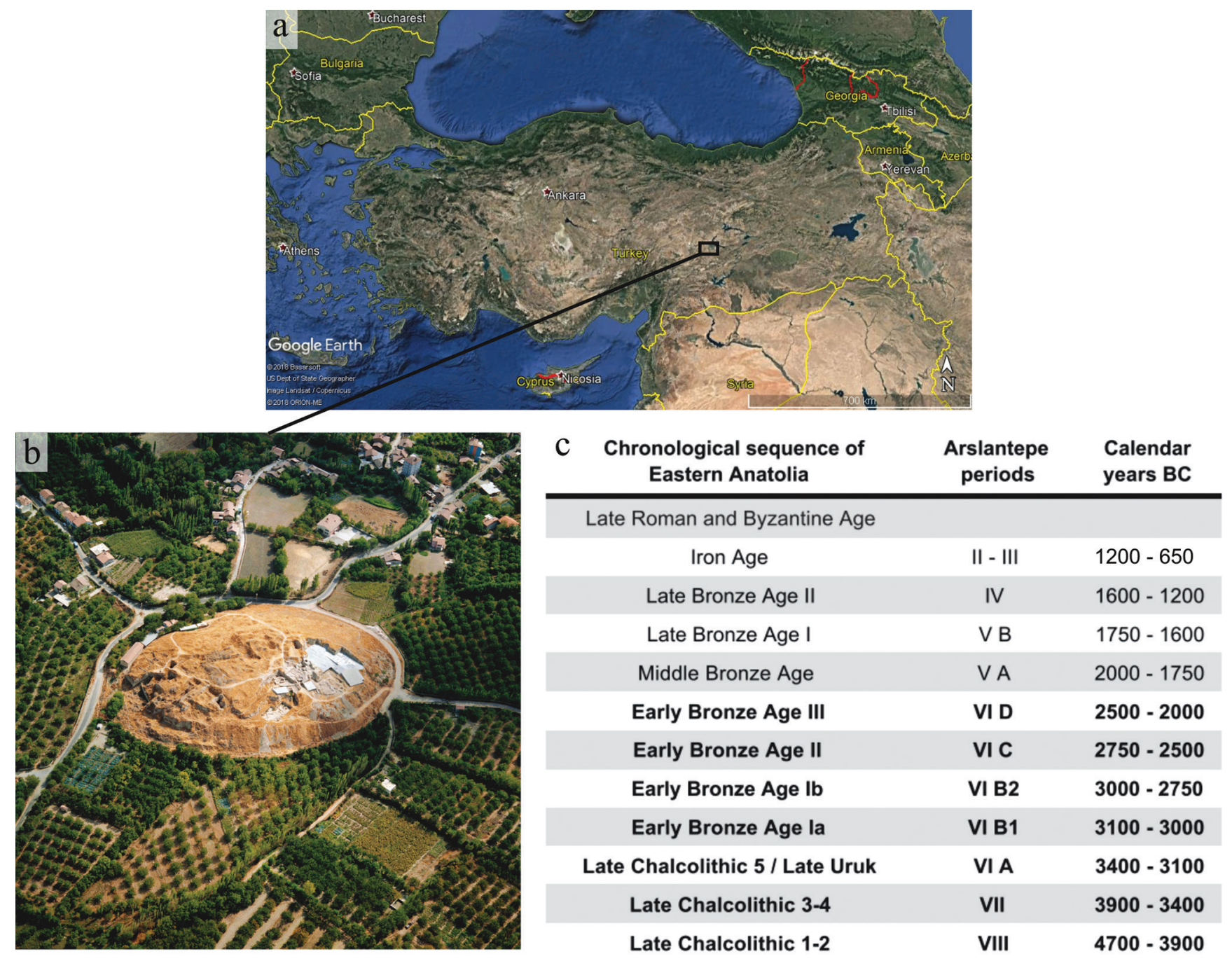

Figure 1. Satellite image of Turkey (a). The black box indicates the location of the Malatya Basin, where the site of Arslantepe arises; b) Aerial photograph of the tell-site of Arslantepe, surrounded by cultivated land (mainly apricot orchards); c) Absolute chronology of Arslantepe. Modified from Vignola et al. (2017) and with new data from Manuelli (2018). Images from MAIAO archive.

they are the result of human recipes, but at the same time parts of living spaces that often require a microstratigraphic analysis as well. As a result, earth construction materials are invariably handled in the handbooks of both ceramic petrography and micromorphology (Karkanas and Goldberg, 2018; Macphail and Goldberg, 2017; Nicosia and Stoops, 2017; Quinn, 2013), even though scientific papers on single case-studies show a prevalence of micromorphologists. In contrast, some other clay-based artefacts, such as loom weights, spools and andirons, are mostly studied by ceramic petrographists, but would strongly benefit from a micromorphological perspective as they are items closely interconnected with the domestic sphere.

\section{Are four eyes better than two?}

Although there is a wide range of archaeological findings that interest both ceramic petrographists and micromorphologists, attempts at data integration rarely occur and are typically limited to discussions about the adoption of common standardised descriptive terminologies (Josephs, 2005; Whitbread, 1995). The ambivalent distance/proximity between these fields was particularly striking for the authors of this paper because of their mutual involvement in the study of earthen materials at Arslantepe (Figure 1), a $30 \mathrm{~m}$ high tell located in the south-east of Turkey, next to the modern city of Malatya. The site, occupied from approximately the $5^{\text {th }}$ millennium BCE to the Byzantine period $\left(4^{\text {th }}-6^{\text {th }}\right.$ century $\mathrm{CE}$ ), has been the object of systematic excavations carried out annually for more than 50 years by a team led by "La Sapienza" University of Rome (Frangipane, 2011). The long and complex occupation sequence of the site allowed the recovery of large amounts of material culture that is studied by several classes of specialists, including - as mentioned before - the two authors of this contribution.

At Arslantepe, Pamela Fragnoli analysed, using thinsection petrography and bulk geochemistry, vessels and 
clay-based artefacts dating from the Late Chalcolithic period to the Middle Iron Age (ca. 4700-712 BCE). Her main aim has been to explore: 1) changes and continuity in raw material procurement patterns and paste preparation modes in relation to the emergence and collapse of the centralised economy; 2) multi-scaled phenomena of mobility ascribable to pastoral communities; 3) relations between socioeconomic complexity, standardisation and specialisation (Fragnoli, 2018; Fragnoli, 2019a; Fragnoli, 2019b; Fragnoli and Palmieri, 2017). Susanna Cereda has instead focused on the micromorphological analysis of earthen surfaces in buildings and open areas in order to reconstruct their microstratigraphy. The main aspect she explored in her investigations was how people engaged with their built environment in terms of its construction, maintenance and use (Cereda, 2019a; Cereda, 2019b; Cereda, in press).

Along with the many shared features connected with their work at the same site (e.g. landscape, environment and raw materials) both Fragnoli and Cereda had included in their research common findings such as either building materials (cob, fireplaces) or objects (andirons, loom weights), which fall into the above-mentioned category of earthen products that pertain to both fields of study, i.e. ceramic petrography and micromorphology. This series of favourable circumstances provided the opportunity for a closer exchange, which in turn encouraged a self-reflection on disciplinary and inter-disciplinary boundaries.

The result of this exchange is the present pilot study on a few selected earth-based findings from Arslantepe, the main aim of which is to assess to what extent the collaboration between ceramic petrographists and micromorphologists might not only be fruitful, but also bring out new research questions and ways of looking at archaeological findings and past human communities. We intend to demonstrate that the integration of data and observations is especially fundamental in archaeological tell sites, where earth and soils could accumulate over millennia and be exploited for craft and domestic activities. Ultimately, this methodological exercise intends to boost the exchange of ideas between the different specialists of the so-called archaeological sciences and enhance interdisciplinarity within interdisciplinarity, in order to think "holistic" beyond any hierarchisation of knowledge (Morin, 1999).

\section{Materials, methods and questions}

For the scope of this contribution, two samples were selected. They belong to different contexts and periods, but they were chosen because they belong to the aforementioned "in-between" categories of earth-based finds. To make the experiment more meaningful and stress the element of inter-disciplinary distance, each author was assigned the type of material she was less familiar with. Fragnoli, the petrographist, was given the construction material (Figure 2): the surface located in the immediate vicinity of a double-vaulted oven (sample 119/16). Cereda, the

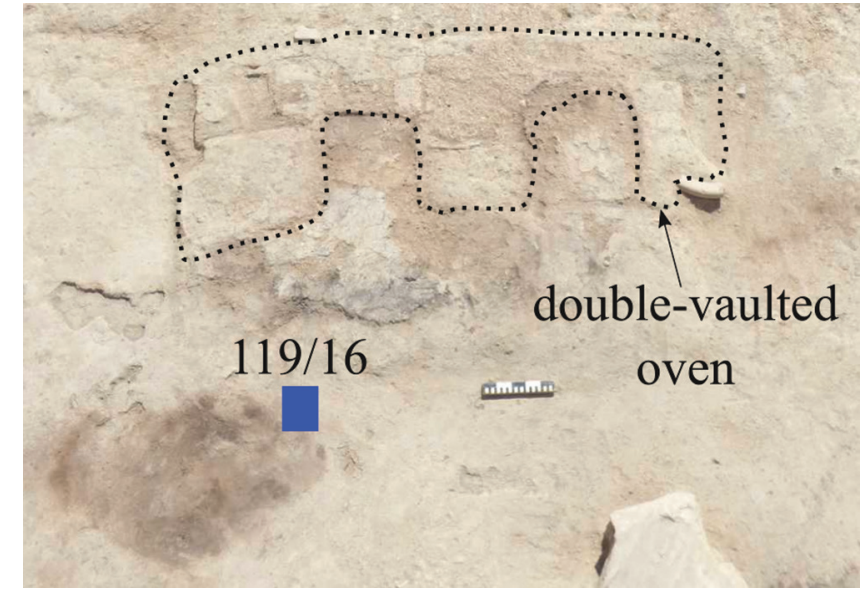

Figure 2. Location of sample 119/16, which was collected directly in front of one of the openings of a double-vaulted oven.

micromorphologist, was assigned the clayey object: sample 205/15 from the andiron (Figure $2 b$ ).

These items were also selected as usually recurring in domestic spaces and differently exposed to fire. The idea is not to provide a detailed description of the thin sections and compare the terminologies used by the different specialists, since ceramic petrography already traditionally borrows the descriptive models of micromorphology (Quinn, 2013; Whitbread, 1995); it is rather an experiment to see whether eyes differently trained might enrich the final interpretations of ancient earth-based finds.

The specific questions that the authors of this contribution asked themselves are: what kind of information would researchers usually focusing on a specific product of the same raw material be able to observe in the artifacts, which are usually examined by the other specialist? What is the common ground they both share and what, in contrast, is the result of the specificities of their objects of study and of the research questions that guide their work, which train their eye differently? And above all: can these figures help each other in the study of earth-based materials?

\section{Results}

\subsection{Fragnoli's analysis of sample 119/16}

Within this sample two main layers could be distinguished based on textural features, different exposures to heat, minero-petrographic associations, and the presence and type of organic matter. The lowest layer (Figures $3 \mathrm{a}-\mathrm{e}$ ) is 1 to $4 \mathrm{~cm}$ thick and consists of a calcareous, optically-active, clay matrix rich in clay pellets with sharp boundaries and high optical density. Among aplastic inclusions the organic matter predominates both in incidence and size (up to $7 \mathrm{~mm} / 20 \%$ ), while minerals are fewer and finer (up to $1.6 \mathrm{~mm} / 5 \%$ ). The angular shapes, low sorting degree, clustered spatial distribution and random-to-discordant orientation patterns of organic components (Figures 3b-d) suggest that they were intentionally added to the clay paste as tempering 

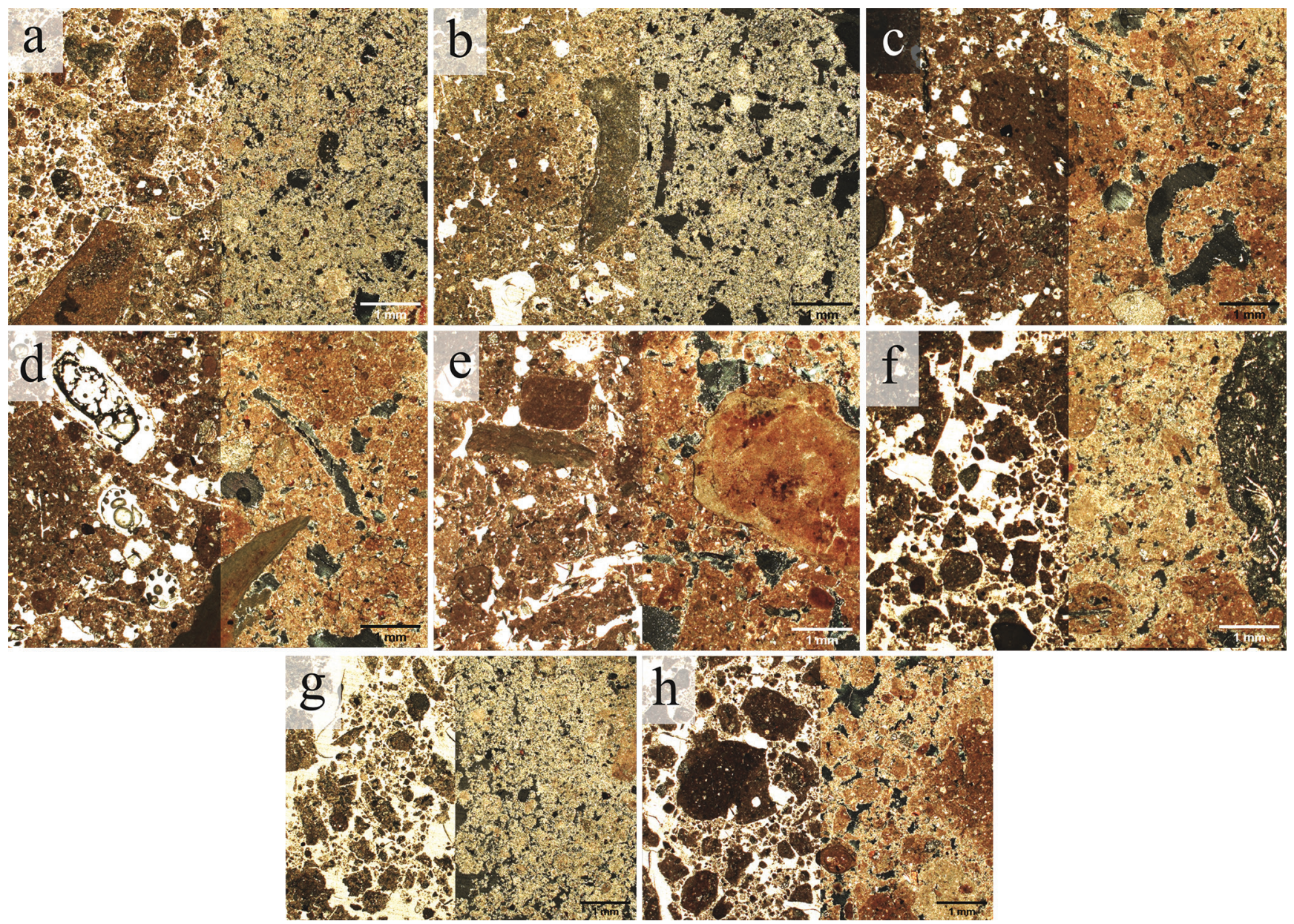

Figure 3. Selection of microphotographs (each one half under PPL and half under XPL) illustrating the main features observed in sample $119 / 16$ (a)-(b) left part of the lowest level characterised by an anisotropic calcareous matrix and mouldic voids without remains of the organic matter originally present; (c)-(e) right part of the lowest level showing a reduced optical activity of the matrix, a lower sorting degree of the inclusions and remains of charred vegetal matter; (f)-(h) upper layer with different grain-size distribution of the loose anisotropic clay particles.

material. Once decomposed they mostly left rectangular voids of different thickness interpretable as imprints of stems and leaves of variegated plants. Only a few arcuate and circular-to-semicircular voids/imprints are ascribable to agricultural by-products, such as cereal spikelets and caryopses. The remaining imprints have more undefined, polylobal-to-polygonal shapes and still contain remains of dark brown organic matter immersed in an orange, glassy matrix (dung temper?). The mineral inclusions of the paste are composed, in order of decreasing incidence, of: micritic calcite, quartz, plagioclase, limestones, intermediate to sialic igneous rocks, amphiboles, biotites, and planktonic foraminifera.

The right part of this lowest layer (Figures 3c-e) differs from the left one (Figures $3 \mathrm{a}-\mathrm{b}$ ) by the decreased sorting degree (polymodal vs. bimodal), the coarser paste ( $6.5 \mathrm{~mm} / 25 \%$ vs. $5.2 \mathrm{~mm} / 15 \%)$, the higher incidence of clay pellets and minerals, the smoother and sharper upper boundaries, the more continuous and regular thickness, as well as the evidence of exposure to heat (lower matrix birefringence and remains of oxidised organic matter).
The above layer (Figures $3 \mathrm{f}-\mathrm{h}$ ) presents a concave shape, up to $5 \mathrm{~cm}$ deep, made of loose rounded-to-subrounded calcareous clay particles of different sizes (ashes?). The clay particles are mostly isotropic, which indicates an exposure to heat or fire. The aplastic inclusions reach a maximum diameter and incidence of $1.76 \mathrm{~mm}$ and $7 \%$ respectively, present a unimodal grain-size distribution, and consist of inclusions of quartz, plagioclase, calcite, limestone, bones, charcoals, melted phytoliths, vegetal matter, planktonic foraminifera, and other bioclasts (shell fragments?). The layer presents significant inner variations: upwards, the compactness, fineness and sorting degree progressively increase, while they tend to decrease towards the external sides.

The two layers identified relate to distinct raw materials and formation processes. The lower one is the result of a recipe prepared and shaped through rotation pressure by humans. This worked material was then partially, briefly and possibly unintentionally exposed to temperatures lower than $800^{\circ} \mathrm{C}$. The intermediate-to-acidic lavas contained in this layer recur in the pottery production of the whole sequence (Fragnoli 
and Palmieri, 2017) and are related to the exploitation of the Baskil and Yüksekova/Elazı ̆̆ complexes located 5.5 $\mathrm{km}$ east from the site (Yagzan and Mason, 1988; Yigitbas and Yilmaz, 1996). The second layer reflects a gradual accumulation process related to successive firing/burning events at temperatures above $800^{\circ} \mathrm{C}$. The minerals indicate a sedimentary environment that fits with the formations on which the site rises (Palmieri, 1978).

\subsection{Cereda's analysis of sample 205/15}

Sample 205/15 (Figure 4) presents a massive structure, combined with a low degree of porosity, which is mainly constituted by vughs and occasional cracks (possibly due to the sample preparation). The $\mathrm{c} / \mathrm{f}$ (coarse/fine) related distribution is close porphyric, with a sandy clay texture that is quite unsorted and presents gravel inclusions. The coarse component is unoriented and randomly distributed. As for its nature, the coarsest mineral fraction includes both volcanic and calcareous aggregates. Among the finer mineral components, plagioclase, quartz and calcite were recognised.

\section{$205 / 15$}

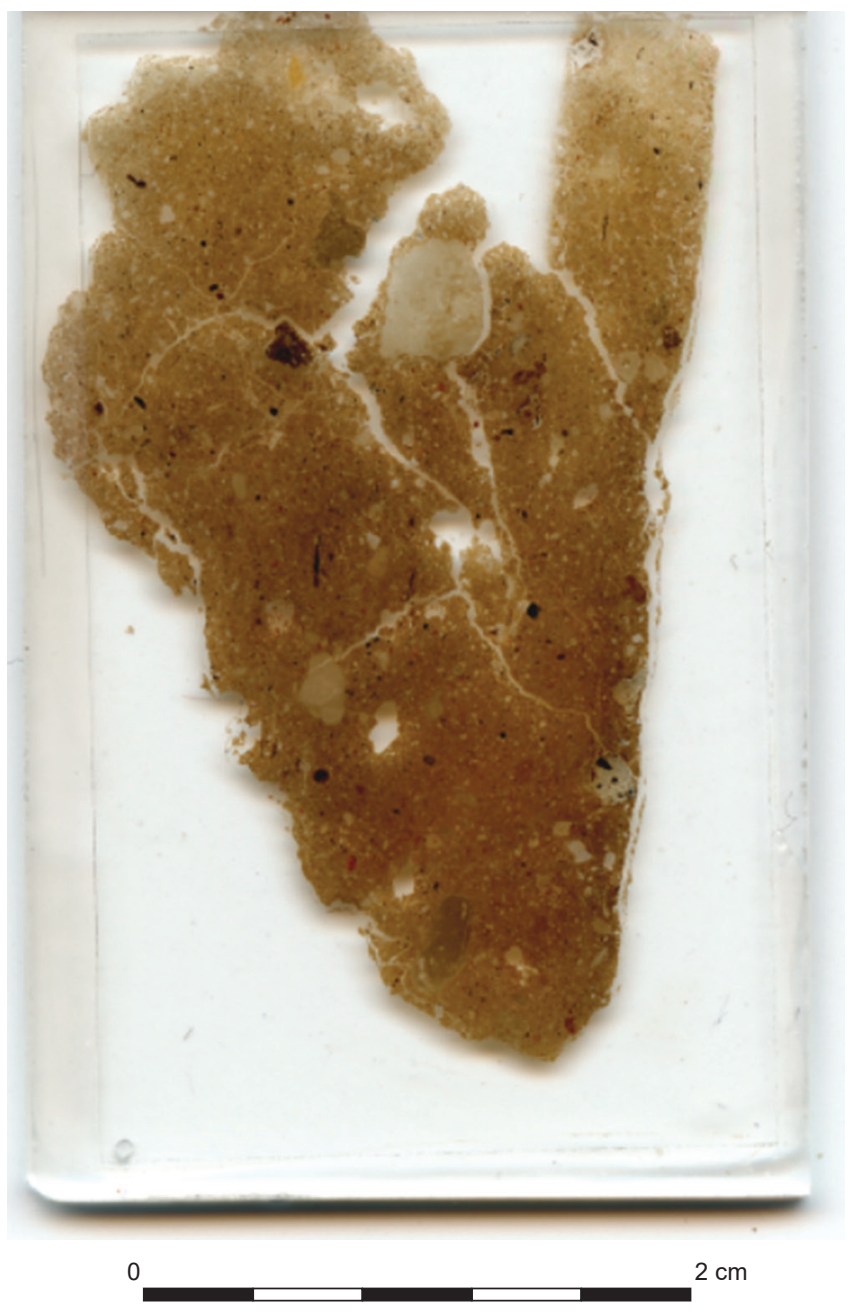

Figure 4. Scan of the andiron sample 205/15.
Anthropogenic and biologic material is well-attested, especially in the form of dung remains - identified in the form of spherulites and phytoliths (Figures $5 \mathrm{f}-\mathrm{g}$ ) - finely trimmed charcoals (Figures 5a, 5c), darkened phytoliths (Figure 5d), dark brown organic matter (Figure 5h) and charred grasses, some shell fragments, bones, a few burnt clay aggregates, one flint flake and a relic soil aggregate with granostriated b-fabric (Figure 5e). Ashes may be present, and their occurrence (interspersed in the groundmass) seems to be supported by the occasional identification of micritic crystals (Figure 5b). The groundmass is reddish/yellowishgrey and presents some redoximorphic features (Fe/Mn stainings), together with some iron oxide nodules. The fine fraction is constituted by a dusty calcareous matrix with crystallitic b-fabric.

The high proportion of occupational debris in the andiron could suggest that the source for this object derives from re-used sediments from within the site - maybe dismantled construction material. The unsorted nature of the deposit and the occurrence of rather coarse inclusions also suggest a poor degree of sieving. The loom weight, on the other hand, presents a more sorted and "cleaner" groundmass, possibly in connection with its different use/function and the need to achieve a less rough texture that could be shaped to a desired form and better manipulated.

\section{Discussion}

\subsection{Reviewing descriptions and interpretations}

Following the description and interpretation of the two samples, results were exchanged and compared. This section reports the discussion that resulted from this comparison, presented in the form of a dialogue.

\subsubsection{Fragnoli's comments and questions}

Except for the terminology used, my observations on sample $205 / 15$ were quite similar. I interpreted the presence of ashes, bones and charcoals, which normally do not occur in ceramic vessels from Arslantepe, as the rest of the domestic activities intentionally re-used as raw materials for producing this clay-based object of everyday life. In analysing other andirons, I even had the impression that the dung included in them was originally used as fuel based on the ash particles present in the voids left by the burnt organic matter. Might that be a diagnostic criterion to distinguish dung incorporated as such from that previously used as fuel for other activities, or does the firing process related to the object's manufacture hinder any possibility of distinction? A similar question would concern other kinds of vegetal tempering materials: how can we distinguish charcoals originated before the artefact was made from plant remains freshly incorporated into the clay paste and only then carbonised by the firing procedures? In cases where phytoliths are not preserved, is there any standard definition of vegetal remains based on the morphology of mouldic voids? What do amorphous matter, burnt clay aggregates, relic soil aggregates and 



Figure 5. Selection of microphotographs illustrating the main features observed in sample 205/15. (a) Dotted groundmass with abundant finely-trimmed charcoals interspersed in a yellowish-grey micritic matrix. Image in PPL. (b) Another detail of the groundmass of the sample. Rhombohedral crystals of micritic ashes can be recognised in the yellow circles. Image in PPL. (c) Charred plant remains, such as in the right side of the picture, can be frequently observed in this sample. The yellow arrows indicate two areas of dark grey $\mathrm{CaCO}_{3}$ enrichment (?). Image in PPL. (d) Dendritic cereal husk phytoliths in an articulated position. The dark coloration of the phytoliths indicates that they were exposed to fire. PPL; (e) Organic sub-rounded pedo-relics, with granostriated b-fabric. Left side: PPL; Right side: XPL. (f) Detail of amorphous light grey degraded dung, characterised by abundant spherulites, whose distinct shape and extinction cross was recognised under crossed nicols. Left side: PPL; Right side: XPL. (g) Fragment of pellet. Here, in contrast to the previous picture (f), the organic matter of the dung is still partly preserved, together with some charred plant matter. Image in PPL. (h) Aggregate of dark brown organic mass of undefined nature in the groundmass. Image in PPL.

$\mathrm{Fe} / \mathrm{Mn}$ staining look like and how were they formed and incorporated into the artefact? Moving to the inorganic inclusions, I could observe in the andiron 205/15 fragments of intermediate-to-acidic lavas in addition to the components that you mentioned. Similar lavas were also recognised in the plaster 119/16 and, as mentioned above, recur in locallyproduced vessels. The shared exploitation of sources, which by the way are not the closest ones available (e.g. the Orduzu volcanic suite is located less than $1 \mathrm{~km}$ from the site), indicates a close correlation, at least in some periods, between pottery manufacture and building activities. Common strategies in the raw material procurement already emerged at a geochemical level between the wheel-finished pottery and mudbricks dating to the Late Chalcolithic 3-4 period (Fragnoli and Liberotti, 2019), but extend now to petrographic features and later periods as well.

\subsubsection{Cereda's reply}

Although I did not recognise the nature (intermediate-toacidic) of the lavas, I noticed in sample 119/16 (the oven plaster) a higher quantity of volcanic rocks compared to the other samples from combustion features I studied in my $\mathrm{PhD}$. First of all, I noticed that this exceptional quantity of volcanic rock corresponds to the context belonging to the latest of the periods I studied (Iron Age), possibly reflecting shifting preferences/needs in the procurement of the main earthen raw material used for the construction of this feature. As for their provenance, I could not provide an exact identification of their source since I conducted no compositional study of different clay outcrops, but interestingly I had assumed a possible provenance from the Orduzu volcanic suite exactly because of the proximity of its deposits to the site. 

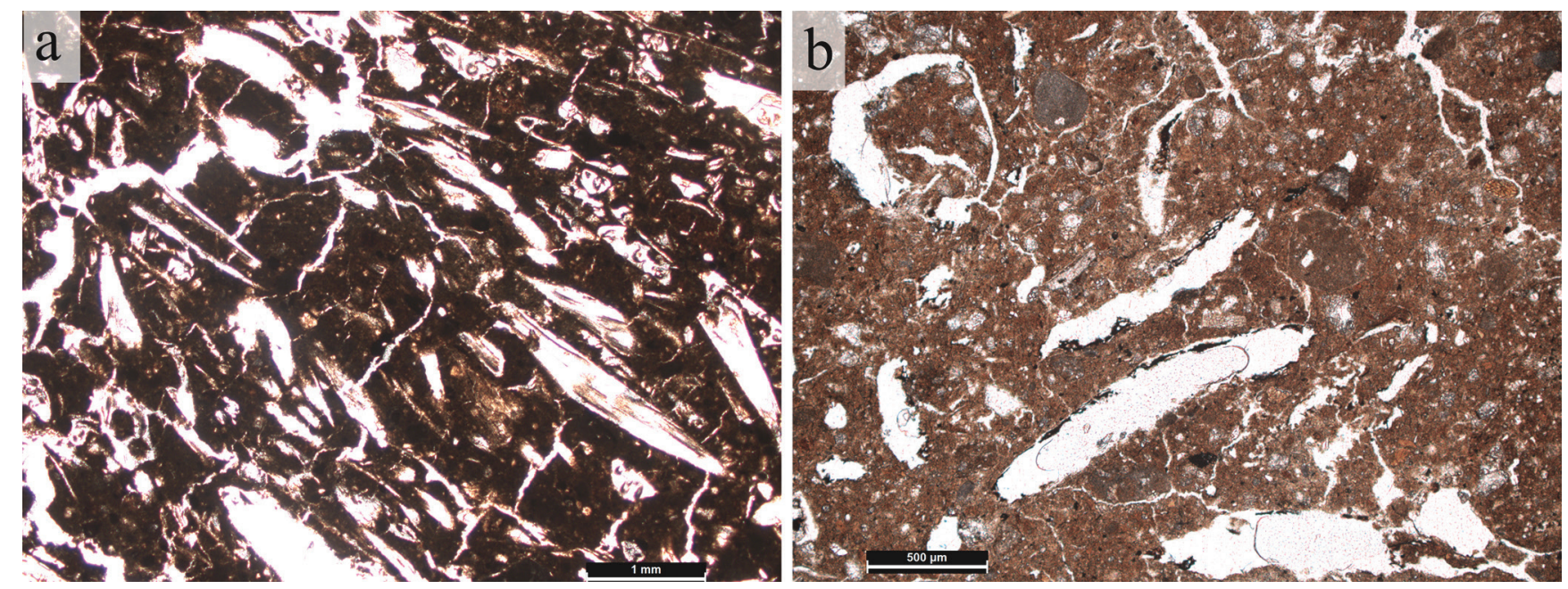

Figure 6. Different morphologies of mouldic voids, often embedding chaff remnants and showing rather angular edges (a); the one in the (b) image presents more rounded edges, possibly associated with straw, charred remnants of which can still be seen towards the void edges.

Concerning the sample 205/15 (the andiron), the ways that some components have been incorporated into the artefact clay paste might go beyond the re-use of domestic activity remains. For example, the preparation of the clay paste may have taken place in outside areas where "contamination" by dirt and occupational debris might easily occur. Alternatively, the composition of the artefact paste could reflect the practice of reusing dismantled building material or of quarrying directly from abandoned/disused areas of the settlement (a form of "sedimentary recycling"). In that case, the occupational debris in the matrix of floors can be understood as background (Dalton, 2017). Most of the samples I analysed from floors and other fixtures in my $\mathrm{PhD}$ had the same "dirty" appearance and exhibited some features, such as "rolling peadofeatures" (Angelucci and Zilhão, 2009) around some plaster or clay nodules, that suggest rotational movements and reworking (Figure $7 \mathrm{~b}$ ).
Burnt dung might have indeed been originally used as fuel, although in this case some of the observed remains show no clear signs of exposure to fire, and they appear degraded rather than burnt. In general, I noticed the regular occurrence of dung in most of the earthen surfaces I have analysed at the site, a feature that reflects the coexistence of people and animals and highlights the contribution of their by-products to the formation history of the site (Koromila et al., 2018). The presence of occasional isolated spherulites, as you noticed, further supports this point and again testifies to the recycled/reworked nature of the deposits used for the fabrication of many objects or fixtures.

As for the other questions, I think that one clue to help distinguish whether an organic component (dung, plants, etc.) was burnt before or after it was mixed with the sediment is given by the degree of shrinkage of the component: if an element appears embedded in the sediment (see the
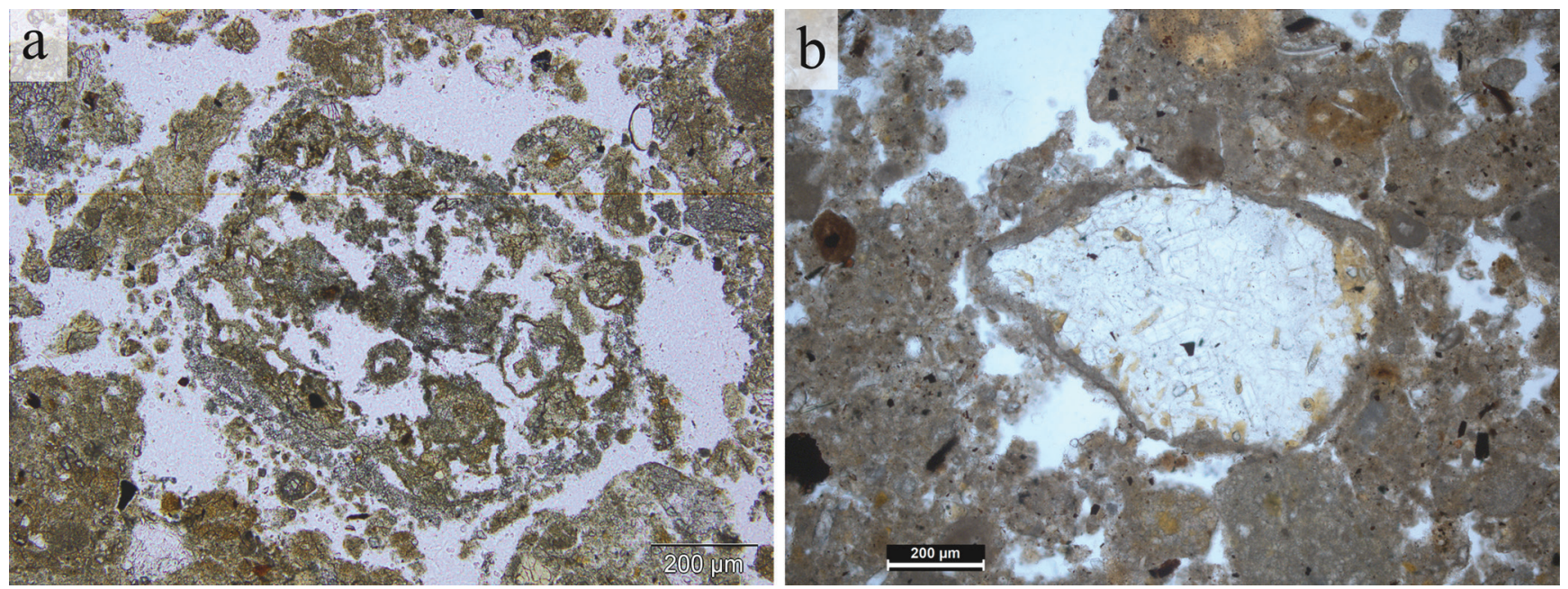

Figure 7. (a) fragment of possible burnt dung pellet in sample 119/16. The original edges of the feature are lined by ashes, which are also visible in the middle of the pellet. (b) Rock fragment with a sub-rounded shape, the edges of which are lined with a thin film of fine clayey material, a so-called 'rolling pedofeature'. Both images are in PPL. 
phytolith in Figure 5d) it would signify that it entered the deposit already in its "final" form, that is burnt or degraded; if instead the organic component is seen within a void (like the fragment of dung pellet in the Figure $5 \mathrm{~g}$ ) its original volume has reduced due to degrading/burning. Even though I am not aware of specific guidelines for the identification of plant remains from mouldic voids I have observed recurring differences between pointy and angular voids, which I associate with chaff temper (Figure 6a), and elongated voids with more rounded edges, possibly connected to the addition of grasses or straw (Figure 6b).

With the term "organic mass" I indicate a stage in which decomposition is advanced and no structure is visible anymore (see Figure 5h), which results in an amorphous substance, or even just a pigment that stains the fine mineral groundmass (Bullock et al., 1985; Stoops, 2003). Redoximorphic features are formed by the reduction and oxidation of iron $(\mathrm{Fe})$ and manganese $(\mathrm{Mn})$ compounds as a result of wetting and drying processes (Stoops, 2003). In this case, a part of these features may have been inherited from the parent material, but others show diffuse boundaries that developed after the construction of the andiron, probably in relation with the manufacturing process itself (pugging).

The soil aggregates, or pedo-relicts, have an organic and sandier groundmass (Figure 2e), with a different b-fabric (striated) than the rest, probably deriving from some reworked horizon (Brewer, 1976). Instead, clay aggregates present a similar fabric and composition with the surrounding matrix. Still, they appear as discrete bodies with rounded shape and sharp boundaries. They are yet another remnant of eroded, reused, embedded, recycled, transported building/construction material. More often than not, it is difficult to recognise the element (mudbrick, floor, object) they originally constituted, but in a sample I studied in my $\mathrm{PhD}$ I observed a direct correspondence between a micritic mud plaster and numerous rounded rip-up clasts embedded in a reconstruction episode of the floor (Cereda, 2019a).

\subsubsection{Cereda's comments and questions}

In sample 119/16 I also observed two layers that correspond to two different formation processes. The lower was indeed identified as an intentional constructed surface, resulting from pugging and mixing of a clay-based material with both mineral and plant additives. Given your familiarity with the technological steps in the manufacturing of pottery, what are for you the characteristics of the deposit that reflect rotation processes? The reddish oxidised groundmass of this lower deposit suggested to me as well the exposure of the lower deposit to fire, but I was not able to formulate a possible temperature range. What are the optical features of the groundmass that hint at this information? As for the upper layer, I did not interpret it as the result of a gradual accumulation, since I could not identify elements of typical accretion such as bedding. Instead, the loose structure of the deposit resembles the chaotic and open organisation of particles following dumping of materials (Karkanas and
Goldberg, 2018; Miller et al., 2010), which in this case are the by-products of burning/fire episodes. Indeed, among the main constituents of this upper layer are not only rounded clay aggregates, but also micritic ashes. I also identified the remnants of a few burnt dung pellets (Figure 7a) a possible comparison also for the dung remains found in sample 205/15, which suggest a mixed use of fuels in this combustion feature. Another difference in the way we analysed the samples consists in what you call "calcareous clay particles", which I called from the beginning ashes (Cereda, 2019b).

\subsubsection{Fragnoli's reply}

As for the lowest layer of 119/16 (plaster from oven), I could recognise evidence of rotation pressure based on the spiraliform and discordant distribution of vegetal temper within the clay paste (Figures $3 b-3 d$ ). In ceramic vessels, such temper distribution typically occurs in cases of coiling-forming techniques (Quinn, 2013). Since the exposure to heat in the form of carbonised matter and reduced birefringence does not concern the whole layer but is limited to its right part, I would exclude an intentional firing intended as a manufacturing step. The temperature range can be only roughly expressed as "equivalent firing temperature" based on the optical activity of the clay matrix and the degree of preservation of some inclusions. We know, for instance, that between 800 and $850^{\circ} \mathrm{C}$ the clay matrix loses its birefringence (Quinn, 2013) and calcite dissociates (Di Caprio, 2007). Since the calcareous matrix of 119/16 is still optically active, we can argue that it was not exposed to temperatures higher than $800^{\circ} \mathrm{C}$.

As for the above layer of 199/16, the term "accumulation" was probably not appropriate; however, I would not call it a chaotic organisation, since there are internal differences in terms of grain-size distribution, which I would have interpreted as the result of similar practices or events that took place at different times (multiple and sequential firing/ burning events?).

From Cereda's description of the andiron 205/15 it emerges again that we often use different terminologies to describe similar features. The terms I normally use to define variations in the clay matrix, in terms of colour, birefringence, composition and grain-size, are either clay pellets or mixing lenses. However, although we adopt distinct descriptive terminologies, we interpret these features in a similar way, namely, as either naturally occurring in the clay deposit or as the result of manufacturing procedures.

\subsection{Evaluating the usefulness of the exercise}

Certainly, the fact that the samples were chosen based on methodological considerations, rather than a precise research aim, made the analysis and the interpretation alone a bit insubstantial, since we were not focused on answering a particular research question. The two samples, decontextualised (besides knowing whether they were objects or fixtures) and described with no archaeological question in mind, were at first difficult to tackle. At the same 
time, such conditions promoted a rather unbiased approach to the deposits, the analysis of which was later broadened with questions triggered by this "pure" observation.

The analysis in itself reveals expected differences in specific terms and definitions, but also an overall consensus regarding the general description and interpretation, which attests to the common background of the two disciplines. A further difference was noted in the number of identified contexts/deposit types. This is again the case of sample 119/16: while Cereda mentioned only one upper context, Fragnoli made a finer distinction in two deposits. Although divergences in observations might happen even between two ceramic petrographists or two micromorphologists, in the present paper they can be understood as a result of not only subjective criteria of categorisation but also a different research focus: while micromorphology deals with the depositional history of sediments and the different processes or events involved in their formation, ceramic petrography prioritises the techno-compositional aspect, which is related to the selection and manipulation of clay sources. This means that while Cereda considered the upper deposit in sample 119/16 from a genetic point of view as discarded ashes and fireplace rake-out, Fragnoli provided a fine-tuned distinction of its composition on the basis of different particle sizes and the distribution of the "calcareous clay particles". Conversely, while Fragnoli relates the raw materials used for the andiron 2015/15 to the exploitation of eastern volcanic sources, Cereda focuses rather on the incorporation and reuse of occupational debris.

At the same time, the different perspective of these two fields provides a valuable learning opportunity. For Cereda, one of the main aspects in which Fragnoli can contribute to her analysis of earthen deposits is related to the more precise identification of minerals and rocks composing them, together with their significance in terms of rawmaterial provenance. Moreover, given their familiarity with the operational steps of ceramic production, other aspects where petrographists can offer relevant insights are the technological steps involved with the manipulation and firing of clays. For Fragnoli, Cereda's eyes provided her the opportunity to look beyond the two main ingredients of the recipe, i.e. clay and inclusions, and get a more nuanced framework on more overlooked anthropogenic and biological factors, whether intentional or accidental, that generated the clay paste as well. The most significant contribution of Cereda on 205/15 concerns the identification of features that the eyes of a ceramic petrographist are not trained to recognise, such as dismantled construction materials and particular organic components - i.e. herbivore dung, pedo-relics and bones exposed to bacterial activity. It is also interesting how Cereda illustrated her description of the sample. Micro-pictures taken under the polarising microscope at various magnifications are accompanied by a scan of the whole thin section. Even though not usual in ceramic petrography, this practice is useful to illustrate general textural and distributional features not visible in the detail of thin section pictures.

\section{Conclusions}

In this paper we presented a methodological exercise of petrographic analysis, using as a case study samples from earthen-based materials from the site of Arslantepe. We both work at this site as micromorphologist and as pottery petrographist. We exchanged samples from earthen objects and fixtures we had already studied in order to compare and evaluate the observations of the other colleague, and thus consider how the perspectives of related disciplines can (if at all) complement each other.

The exercise was qualitative in nature and the limited number of samples as well as the involvement of only two people do not allow for broad generalisations. Moreover, the subjectivity of individual experience and years of practice needs to be taken into account. Nonetheless, results showed that the descriptions did capture in both cases the nature and interpretation of the features analysed - thus reflecting a main common "framework" - and added useful details, which confirmed but also broadened original interpretations or provided further questions.

All in all, our findings contribute to stressing the importance of dialogue and communication among specialists in different fields in archaeological sciences. Certainly, a transfer of knowledge already occurs among colleagues within the same disciplines, but this does not decrease the importance of establishing a similar dialogue between micromorphologists and ceramic petrographists as well. Indeed, while separate meetings and workshops for micromorphologists and ceramic archaeometrists regularly take place, we believe that it would be more desirable to bring together in such workshop experts from both fields, so as to facilitate the exchange of information and ideas directly over the microscope. Furthermore, the definition and interpretation of some recurrent features, such as animal bones, herbivore dung and plant remains would noticeably benefit (especially in the field of ceramic petrography) from the combined participation of archaeobotanists and zooarchaeologists. The integration of multiple realms of expertise and different focal interests, ideally combined to develop projects with common research questions, will further establish optical petrography as a key tool for the study of earthen-based archaeological materials, and hopefully promote it as a potential bridge between organic- and inorganic-based disciplines, which in archaeology are still too often maintained in separate camps.

\section{Acknowledgments}

We would like to thank Irmgard Hein for organising the Workshop "Archaeological Finds \& Analytical Methods", which provided the opportunity for an exchange between scholars from different backgrounds and inspired this article. Also, special thanks go to Marcella Frangipane, Francesca Balossi Restelli and all our colleagues working in Arslantepe, whose constant support and precious collaboration we are very grateful for. 


\section{References}

ANGELUCCI, D.E., ZILHÃO; J., 2009. Stratigraphy and Formation Processes of the Upper Pleistocene Deposit at Gruta da Oliveira, Almonda Karstic System, Torres Novas, Portugal. Geoarchaeology, 24, 277-310.

BREWER, R., 1976. Fabric and Mineral Analysis of Soils. Huntington, NY: Robert E. Krieger Publishing Co.

BULlOCK, P., FEDOROFF, N., JONGERIUS, A., STOOPS, G., TURSINA, T., BABEL, U., 1985. Handbook for soil thin section description. Wolverhampton: Waine Research Publication.

CEREDA, S., 2019a. Micromorphological analyses from the floor of the main room in Temple D: reconstruction of activities and rebuilding phases. Contribution to: M. Frangipane: "A new assemblage of cretulae and seal images from Temple D. Stratigraphic and functional remarks". In: F. Balossi Restelli, ed. Arslantepe. Period VII. The Development of a ceremonial/political centre in the first half of the $4^{\text {th }}$ millennium BCE (LC 3-4). Rome: Arbor Sapientiae Editore, pp. 216-221.

CEREDA, S., 2019b. What's under the carpet? - The integration of geoarchaeological analyses for a spatial definition of human behaviours at Arslantepe (Malatya, Turkey). Unpublished thesis (PhD), University of Vienna.

CEREDA, S., in press. Microarchaeological data from Buiding XXXVII and courtyard A1414. Contribution to: M. Frangipane: "New forms of political expressions and ideological manipulation at the dawn of State formation. The evidence from $4^{\text {th }}$ millennium Arslantepe, Turkey". In: K.R. Morgan, ed. Pomp, Circumstance, and the Performance of Politics: Acting Politically Correct in the Ancient World. Chicago: OIS (Oriental Institute Seminar Publications).

COURTY, M.-A., FEDOROFF, N., 1982. Micromorphology of a Holocene dwelling. PACT, 7, 257-277.

DALTON, M., 2017. Reconstructing lived experiences of domestic space at Amara West: Some preliminary interpretations of ancient floor deposits using ethnoarchaeological and micromorphological analyses. In: N. Spencer, M. Binder and A. Stevens, eds. Nubia in the New Kingdom: lived experience, pharaonic control and indigenous traditions. Leuven, Belgium: Peeters, 2017, pp. 357-388.

FRAGNOLI, P., 2018. Pottery production in pastoral communities: Archaeometric analysis on the LC3-EBA1 Handmade Burnished Ware from Arslantepe (in the Anatolian Upper Euphrates). Journal of Archaeological Science: Reports, 18, 318-332.

FRAGNOLI, P., 2019a. The introduction of the potter wheel in Arslantepe's period VII: integrated observations on a micro-, meso- and macroscale level. In: F. Balossi Restelli, ed. Arslantepe. Period VII. The Development of a ceremonial/political centre in the first half of the $4^{\text {th }}$ millennium BCE (LC 3-4). Rome: Arbor Sapientiae Editore, pp. 345-357.

FRAGNOLI, P., 2019b. (Re)defining ceramic wares and spheres of production in Arslantepe's period VII. The contribution of petrographic and geochemical analyses. In: F. Balossi Restelli, ed. Arslantepe. Period VII. The Development of a ceremonial/political centre in the first half of the $4^{\text {th }}$ millennium $B C E$ ( $L C$ 3-4). Rome: Arbor Sapientiae Editore, pp. 357-367.

FRAGNOLI, P., LIBEROTTI, G., 2019. Cross-craft strategies in raw material procurement: ceramics, mud bricks and other clay-based artefacts. In: F. Balossi Restelli, ed. Arslantepe. Period VII. The Development of a ceremonial/political centre in the first half of the $4^{\text {th }}$ millennium $B C E$ ( $L C$ 3-4). Rome: Arbor Sapientiae Editore, pp. 367-380.
FRAGNOLI, P., PALMIERI, A.M., 2017. Petrographic and geochemical investigations on the pottery production from Arslantepe-Malatya (Eastern Anatolia) from $4^{\text {th }}$ to $2^{\text {nd }}$ millennium BCE: technological continuity, innovation and cultural change. Archaeometry, 59, 612-641.

FRANGIPANE, M., 2011. Arslantepe-Malatya: A Prehistoric and Early Historic Center in Eastern Anatolia: In: G. McMahon and S.R. Steadman, eds. The Oxford Handbook of Ancient Anatolia: (10,000-323 BCE). New York: Oxford University Press, pp. 968-992.

GOLDBERG, P., 1979. Geology of Late Bronze Age Mudbrick from Tel Lachish. Tel Aviv, 6, 60-67.

GOLDBERG, P., 1980. Micromorphology in archaeology and prehistory. Paléorient, 6, 159-164.

JOSEPHS, R.L., 2005. Short contribution: Applying micromorphological terminology to ceramic petrography. Geoarchaeology, 20, 861-865.

KARKANAS, P., GOLDBERG, P., 2018. Reconstructing Archaeological Sites: Understanding the Geoarchaeological Matrix. Hoboken, NJ: John Wiley \& Sons Ltd.

KOROMILA, G., KARKANAS, P. HAMILAKIS, Y, KYPARISSIAPOSTOLIKA, N., KOTZAMANI, G., HARRIS, K., 2018. The Neolithic tell as a multi-species monument: Human, animal, and plant relationships through a micro-contextual study of animal dung remains at Koutroulou Magoula, central Greece. Journal of Archaeological Science: Reports, 19, 753-768.

MACPHAIL, R.I., GOLDBERG, P., 2017. Applied Soils and Micromorphology in Archaeology. Cambridge: Cambridge University Press.

MANUELLI, F., 2018. Drifting Southward? Tracing Aspects of Cultural Continuity and Change in the Late $2^{\text {nd }}$ Millennium BC Syro-Anatolian Region. Studia Eblaitica, 4, 139-186.

MILLER, C.E., CONARD, N.J., GOLDBERG, P., BERNA, F., 2010 Dumping, sweeping and trampling: Experimental micromorphological analysis of anthropogenically modified combustion features P@lethnologie, 2, 25-37.

MORIN, E., 1999. La Tête Bien Faite. Repenser la Réforme, Réformer la Pensée. Paris: Seuil.

NICOSIA, C., STOOPS, G., 2017. Archaeological Soil and Sediment Micromorphology. Hoboken, NJ: John Wiley \& Sons Ltd.

PALMIERI, A.M., 1978. Studio Sedimentologico dell'Area Nord-Orientale di Arslantepe. Quaderni de "La Ricerca Scientifica", 100, 353-364.

QUINN, P.S., 2013. Ceramic Petrography: The Interpretation of Archaeological Pottery and Related Artefacts in Thin Section. Oxford: Archaeopress.

STOOPS, G., 1984. Petrographic study of mortar and plaster samples, Dissertationes Archaeologicae Gardenses, 22, 164-170.

STOOPS, G., 2003. Guidelines for Analysis and Description of Soil and Regolith Thin Sections. Madison: Soil Science Society of America, Inc.

VIGNOLA, C., MASI, A., BALOSSI RESTELLI, F., FRANGIPANE, M., MARZAIOLI, F., PASSARIELLO, I., STELLATO, L., TERRASI, F., SADORI, L., 2017. $\delta 13 \mathrm{C}$ and $\delta 15 \mathrm{~N}$ from14C-AMS dated cereal grains reveal agricultural practices during 4300-2000 BC at Arslantepe (Turkey). Review of Palaeobotany and Palynology, 247, 164-174.

WHITBREAD, I.K., 1995. Greek Transport Amphorae: A Petrological and Archaeological Study. Athens: British School at Athens.

YAZGAN, E., MASON, R., 1988. Orbicular gabbro near Baskil, Southeastern Turkey. Mineralogical Magazine, 52, 161-173.

YIĞITBAS, E., YILMAZ, Y., 1996. New evidence and solution to the Maden Complex controversy of the southeast Anatolian orogenic belt (Turkey). Geologische Rundschau, 85, 250-263. 